\title{
The Records of Ming Scholars
}



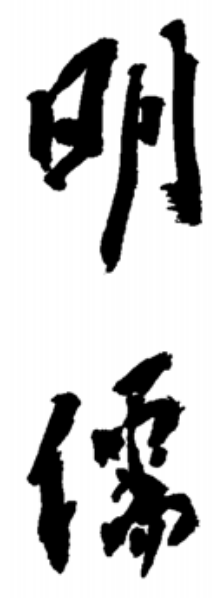

B

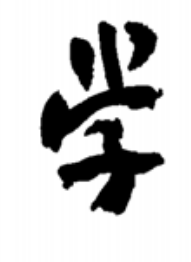

放
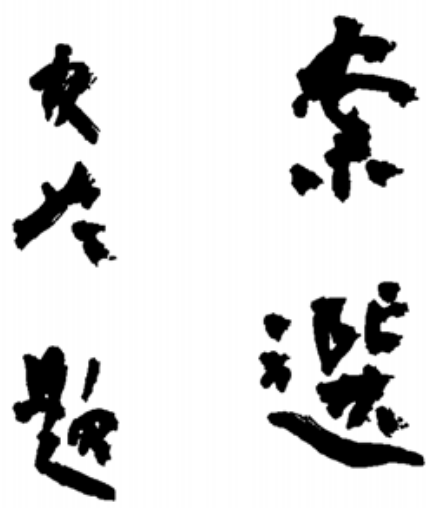

$$
\text { 谱 }
$$




\section{The Records \\ of Ming Scholars}

by

Huang Tsung-hsi

A Selected Translation

edited by Julia Ching

with the collaboration of

Chaoying Fang 
(C) 1987 University of Hawaii Press

All Rights Reserved

Manufactured in the United States of America

Library of Congress Cataloging-in-Publication Data

Huang, Tsung-hsi, 1610-1695.

The records of Ming scholars.

Translation of: Ming ju hsüeh an.

Bibliography: p.

Includes indexes.

1. Learning and scholarship-China. 2. ScholarsChina. I. Ching, Julia. II. Fang, Chao-ying, 1908- . III. Title.

$\begin{array}{llll}\text { AZ791.H7982513 } 1987 & 001.2 ' 0951 & \text { 86-27257 }\end{array}$

ISBN 0-8248-1028-7 
The editor wishes to dedicate this book

to Tsen-chüeh Tsao and Wing-tsit Chan 